\title{
Microstructure and oxidation behaviour of Euro IV diesel engine soot: a comparative study with synthetic model soot substances
}

\author{
D.S. Su*, a , R.E. Jentoft ${ }^{\text {a }}$, J.-O. Müller ${ }^{\text {a }}$, D. Rothe ${ }^{\text {b }}$, E. Jacob ${ }^{b}$, C.D. Simpson ${ }^{\text {c }}$, \\ Ž. Tomovićc ${ }^{\text {, K. Müllen }}{ }^{\mathrm{c}}$, A. Messerer ${ }^{\mathrm{d}}$, U. Pöschl ${ }^{\mathrm{d}}$, R. Niessner ${ }^{\mathrm{d}}$, R. Schlögl ${ }^{\mathrm{a}}$ \\ a: Department of Inorganic Chemistry, Fritz-Haber-Institute der Max-Planck-Gesellschaft, \\ Faradayweg 4-6, D-14195 Berlin, Germany \\ ': MAN Nutzfahrzeuge Gruppe Geschäftsbereich Motoren, Abt. MTVN, Vogelweiherstr. 33, \\ D-90441 Nürnberg, Germany \\ ': Max-Planck-Institut für Polymerforschung, Ackermannweg 10, D-55128 Mainz, Germany \\ d: Institute of Hydrochemistry, Technical University of Munich, Marchioninistraße 17, \\ D - 81377 München, Germany
}

\begin{abstract}
In this study, the microstructure and oxidation behaviour of soot from the raw exhaust of a Euro IV test heavy duty (HD) diesel engine is investigated and compared to that of spark discharge soot and hexabenzocoronene $\left(\mathrm{HBC}, \mathrm{C}_{42} \mathrm{H}_{18}\right)$. We find a microstructure-controlled reactivity toward oxidation of all three samples in $5 \% \mathrm{O}_{2}$ in $\mathrm{N}_{2}$. The spark discharge soot with its fine primary particles and fullerenoid structure has an onset temperature of $423 \mathrm{~K}$ for combustion, while the hexabenzocoronene with its well-ordered crystallites has a high onset temperature of $773 \mathrm{~K}$. Due to an improved combustion process in the Euro IV HD diesel engine, the soot emitted consists of more fullerenoid-like or onion-like particles agglomerated in a chain-like secondary structure. The onset temperature of the Euro IV HD engine soot combustion is $573 \mathrm{~K}$. Oxidation of the three samples produces only $\mathrm{CO}_{2}$ and $\mathrm{H}_{2} \mathrm{O}$. The different $\mathrm{H}_{2} \mathrm{O}$ production profiles can be assigned to the functionalised surface of the samples and depend on the soot structures and preparation route.
\end{abstract}

Keywords: Soot oxidation, Soot microstructure, Euro IV HD diesel engine soot, HBC,

\footnotetext{
* Corresponding author: dangsheng@fhi-berlin.mpg.de
} 


\section{Introduction}

Recently, soot particles from diesel engines have become an important topic in environmental, scientific, and political discussions. European legislation on particulate matter (PM) emissions has made significant advancement with the adoption of limit value standards up to and including Euro IV for heavy duty (HD) engines. Efforts to reduce soot particulate from automotive engine exhaust have proceeded in two directions: optimisation of the combustion process to achieve a burnout of fuel to the highest possible extent, and development of technologies for the treatment of soot particulate in the engine exhaust train [1].

This second direction, so called "after-treatment" of soot, is based on the installation of filter monoliths in the exhaust line that must be periodically regenerated by burning the soot deposited on the traps. Soot particulate filters are effective in reducing the emission rate and have been applied in buses and passenger cars, but they suffer from the shortcomings that they can be blocked by ash from engine lubrication oil resulting in high back pressure which reduces combustion efficiency and engine power, leading to increased fuel consumption. A more promising alternative for the after-treatment of soot to achieve Euro IV HD engine

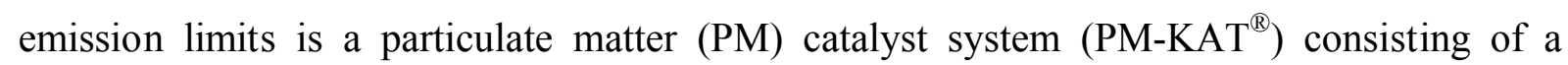
platinum oxidation catalyst and metallic substrates with open cells for storage and oxidation of soot [2]. The remarkable advantage of the PM catalyst system compared to standard particulate filters is its open cell structure and therefore the relatively low flow resistance. Testing on a strong black smoking emission engine shows that only a small back pressure is produced and no blocking of the device is observed [2].

For both after-treatment systems, the oxidation (gasification) of the soot has to take place for regeneration of the devices. In fact, the oxidation of soot has been widely investigated because it is of great significance for pollution control not only in automobile engines, but 
also in industrial flames [3]. $\mathrm{O}_{2}, \mathrm{CO}_{2}, \mathrm{H}_{2} \mathrm{O}$, and $\mathrm{NO}_{2}$ oxidise and gasify soot, with $\mathrm{NO}_{2}$ being the most reactive at low temperatures. The oxidation pathway involves interaction between adsorption and desorption processes that determine the primary products, the order of the reaction and the activation energy. However, many conclusions derived from experimental results are made on the assumption that soots from various sources are structurally related and similar to commercial carbon blacks that are often used in soot oxidation experiments [4].

Recently, it was reported that the microstructure of soot particles depends on synthesis conditions such as burning temperature, time, and initial fuel identity [5]. Soots from pyrolysis of benzene, ethanol, and acetylene exhibit different microstructures and correspondingly oxidation rates that can differ by nearly fivefold. It is reasonable to raise the question of whether the improved combustion conditions alter the microstructure of soot particulates and thus also change the reactivity towards oxidation, a question that is of importance both for combustion optimisation and for the after-treatment of soot. In a preliminary study we found that the microstructure of soot emitted from a low emission Euro IV HD diesel engine was different from that of a Euro III HD engine running in black smoke mode, and that consequently the oxidation behaviour of the soot was different [6]. In this paper we present the results of a comparative study on microstructure and oxidative behaviour of the Euro IV HD soot, spark-discharge soot (GFG), and hexabenzocoronene (HBC) stressing the significance of the microstructure-controlled oxidative property of Euro IV HD diesel soot and the possible consequence for air pollution controls.

Soot is built from so called basic structural units (BSU), consisting of graphene segments with six-membered carbon rings [7]. Large polycyclic aromatic hydrocarbons (PAH) consisting of up to 37 benzene rings can be chosen as two-dimensional models of carbon with graphenelike structure. As a first candidate, the highly symmetric $\mathrm{HBC}\left(\mathrm{C}_{42} \mathrm{H}_{18}\right)$ is employed in the present work to serves as a model for the BSU of soot particles. It is a so-called all-benzoid 
PAH, which, according to Clar's concept [8], can be drawn with rings containing either $6 \pi$ electrons or none. The hydrocarbon has a diameter of $1.5 \mathrm{~nm}$. At the same time, soot produced by spark-discharge from a graphite rod with it's strongly curved fullerenoid structure containing also five-membered rings of carbon atoms was chosen as a contrasting soot model, considering that diesel soot particles are more defect-rich and curved than welldefined graphite.

\section{Experimental}

The Euro IV HD soot was produced in a Euro IV HD test diesel engine of the MAN group. Details about the engines and soot collection have been described elsewhere [9]. Spark discharge soot (GfG) was produced with an aerosol generator (GfG 1000, Palas GmbH, Karlsruhe) operated with two graphite electrodes (CRG München, 200 ppm ashes), $150 \mathrm{~Hz}$ discharge frequency, and 4 1/min argon carrier gas flow [10,11]. Several pathways for the synthesis of hexa-peri-hexabenzocoronene are described in the literature, oxidative cyclodehydrogenation of hexaphenylbenzene (1, HPB) with copper(II) triflate and aluminum(III) trichloride is applied in the present work [12, 13].

A Philips TEM/STEM CM 200 FEG transmission electron microscope equipped with a fieldemitting gun was used to study the morphology and microstructure of the soot. The acceleration voltage was set to $200 \mathrm{kV}$.

For thermo-gravimetric (TG) measurements the procedures were as follows: The TG/DSC data was measured using a Netzsch-STA 449 instrument with $\mathrm{Al}_{2} \mathrm{O}_{3}$ crucibles. The samples were evacuated and the sample chamber was re-filled with $5 \% \mathrm{O}_{2}$ in $\mathrm{N}_{2}$ which was maintained at a total flow rate of $100 \mathrm{ml} / \mathrm{min}$. A heating rate of $5 \mathrm{~K} / \mathrm{min}$ was used. The gas phase products were transferred through a heated quartz capillary to a Balzers, OmniStar 
quadrupol mass spectrometer operated in SIM mode. The only products observed were $\mathrm{CO}_{2}$ (m/e 44-46) and $\mathrm{H}_{2} \mathrm{O}$ (m/e 17-18). The sample charge used for TG analysis was about $2 \mathrm{mg}$.
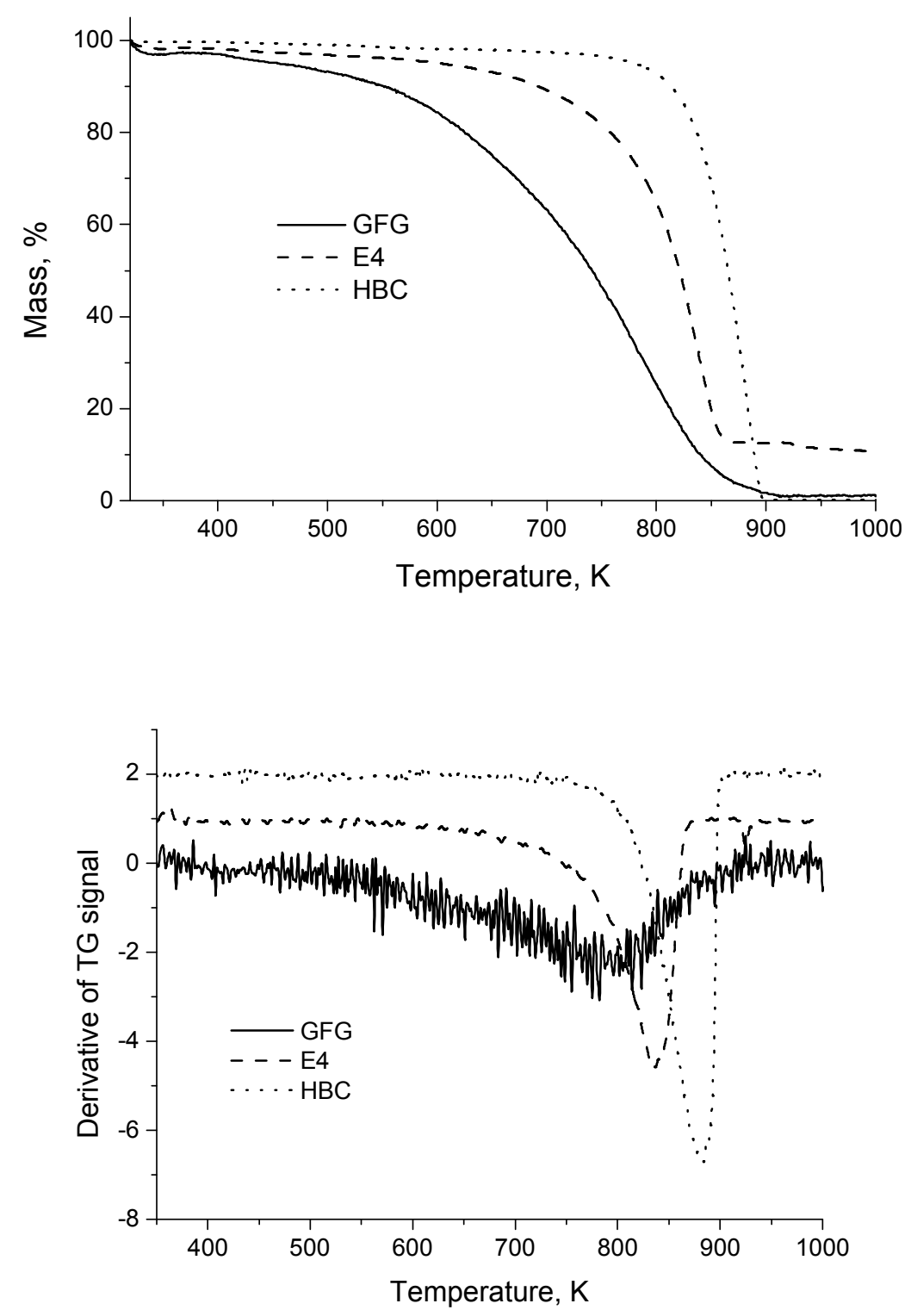

Fig.1 A: TPO-analysis of GfG, E4 and HBC. B: Derivative of the TG signal for GfG, E4, and HBC samples (offset for clarity) 


\section{Results}

Figure 1A shows the results of TG analysis in $5 \% \mathrm{O}_{2}$ in $\mathrm{N}_{2}$ for the soot samples. The GfG soot is more prone to gasification than either the HBC or the Euro IV HD soot, and begins to loose mass at about $420 \mathrm{~K}$. The rate of mass loss increases continuously and reaches a maximum at about $780 \mathrm{~K}$ (Fig. 1B). The sample is completely gasified at a temperature of $920 \mathrm{~K}$. The TG signal for Euro IV HD soot remains nearly constant until about $570 \mathrm{~K}$ when the sample begins to rapidly loose mass. The rate of mass loss for the Euro IV sample reaches a maximum at $835 \mathrm{~K}$. The rate of mass loss goes to nearly zero after $88 \%$ of the sample is gasified by $880 \mathrm{~K}$. There is an additional small mass loss at $920 \mathrm{~K}$ leaving a final residue of $\sim 10 \%$ of the initial weight after the sample has been heated to $1070 \mathrm{~K}$. The matter remaining at the end of the experiment was found to be the ash of engine lubrication oil. The sample of $\mathrm{HBC}$ is stable to about $730 \mathrm{~K}$ at which temperature it begins to loose mass rapidly. The mass loss rate reaches a maximum at about $880 \mathrm{~K}$ (Fig. 1B), and the sample is completely consumed after reaching a temperature of about $890 \mathrm{~K}$.

For all three samples the produced gas analysis shows that the main product is $\mathrm{CO}_{2}$ with a lesser amount of $\mathrm{H}_{2} \mathrm{O}$ (Fig. 2). No other gas phase products were observed. The GfG soot begins to evolve $\mathrm{CO}_{2}$ at about $420 \mathrm{~K}$, and the $\mathrm{CO}_{2}$ evolution has a shoulder at about $620 \mathrm{~K}$ and a maximum at about $790 \mathrm{~K}$, coinciding with the maximum rate of mass loss. The GfG soot evolves $\mathrm{H}_{2} \mathrm{O}$ over the same temperature range as it loses $\mathrm{CO}_{2}$, but the maximum in $\mathrm{H}_{2} \mathrm{O}$ loss occurs at about $620 \mathrm{~K}$ coinciding with the shoulder in the $\mathrm{CO}_{2}$ evolution curve. The evolution of $\mathrm{H}_{2} \mathrm{O}$ goes through a second, local maximum at about $790 \mathrm{~K}$. Gas phase analysis during the combustion of Euro IV HD soot shows that $\mathrm{CO}_{2}$ evolution begins at about $570 \mathrm{~K}$ and increases with temperature to a maximum at $830 \mathrm{~K}$, corresponding to the maximum in the rate of mass loss. A corresponding signal for the evolution of $\mathrm{H}_{2} \mathrm{O}$ from the Euro IV HD soot also begins at about $570 \mathrm{~K}$, and reaches a maximum at about $830 \mathrm{~K}$. HBC begins to evolve 
$\mathrm{H}_{2} \mathrm{O}$ from the $\mathrm{HBC}$ sample begins at about $470 \mathrm{~K}$ and reaches a maximum at about $880 \mathrm{~K}$, coinciding with the maximum evolution of $\mathrm{CO}_{2}$ and the maximum rate of mass loss for this sample
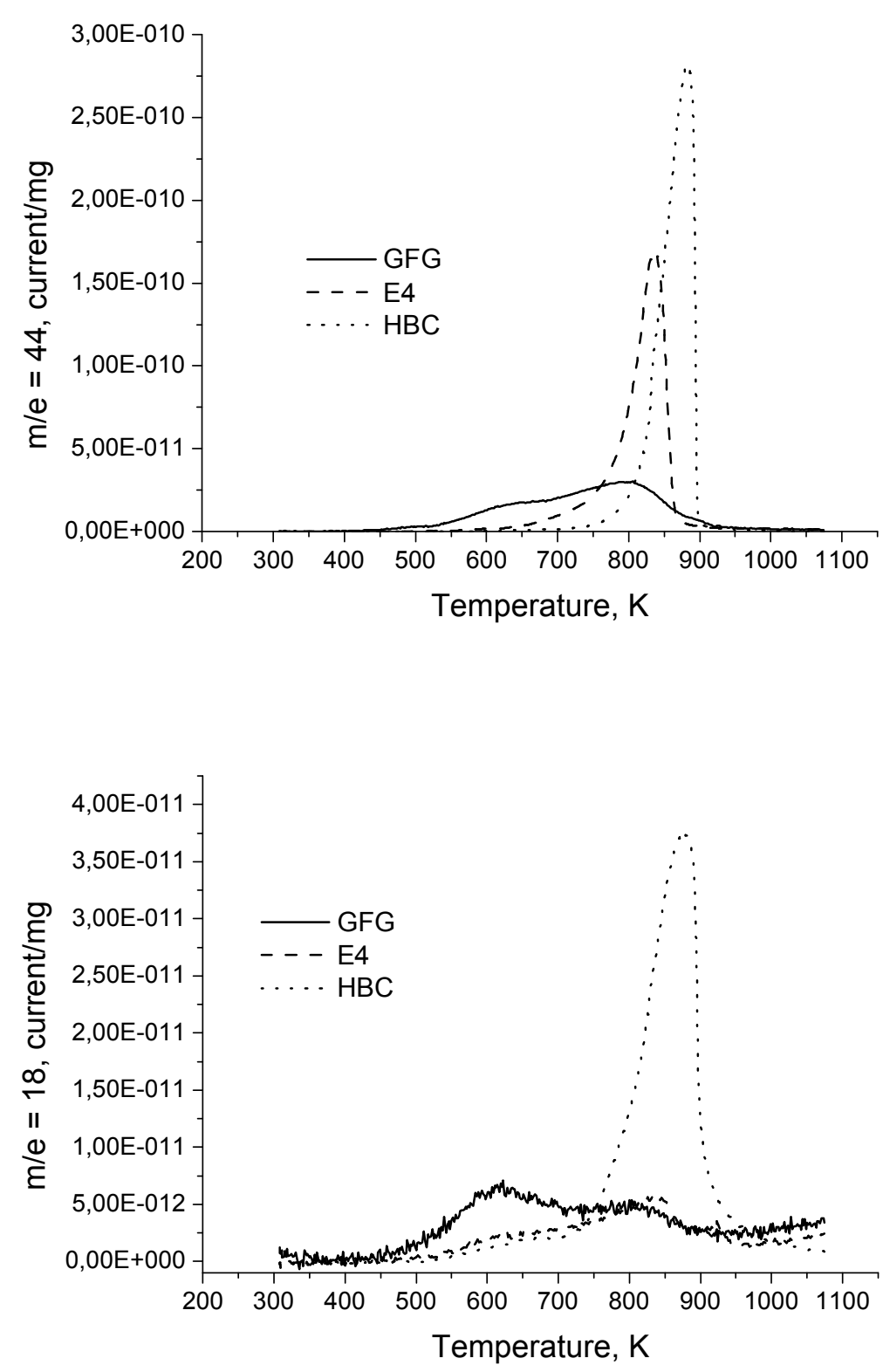

Fig.2 A: MS-data for $\mathrm{m} / \mathrm{e}=44\left(\mathrm{CO}_{2}\right)$. B: MS data for $\mathrm{m} / \mathrm{e}=18\left(\mathrm{H}_{2} \mathrm{O}\right)$. 
Fig. 3 shows the high-resolution electron micrographs of the three soot samples. The Euro IV HD soot (Fig. 3a, 3b) consists of primary particles of 3 to $15 \mathrm{~nm}$ in diameter, agglomerated in chain-like secondary structure typical for carbon black. The averaged particle size is much smaller than the expected primary spherules of soot or carbon black which average $20-30$ nm. The Euro IV HD soot exhibits extended graphene segments as basic structure units. The carbon is made from much larger units of $\mathrm{sp}^{2}$ carbon that form interlaced bundles of ribbons with eventual large areas of planar interconnection. The primary units are bands of carbon with multiple continuous bending. The GfG soot consists of homogeneous spherical particles with a very narrow size distribution of about $3 \mathrm{~nm}$. The graphene segment is strongly bent forming single or double-layered fullerenoid-like structures (Fig. 3c, 3d), coagulated to agglomerates. The micrograph in Fig. 3e reveals that the HBC platelet consists of extended carbon lamella structure with large strands of well-ordered (parallel to each other) basic structural units. The enlarged high-resolution image in Fig. 3f, shows the herringbone structure of a HBC platelet with well defined long-range ordering, in contrast to GfG and Euro IV HD soot as shown in Fig. 3a and 3b. 

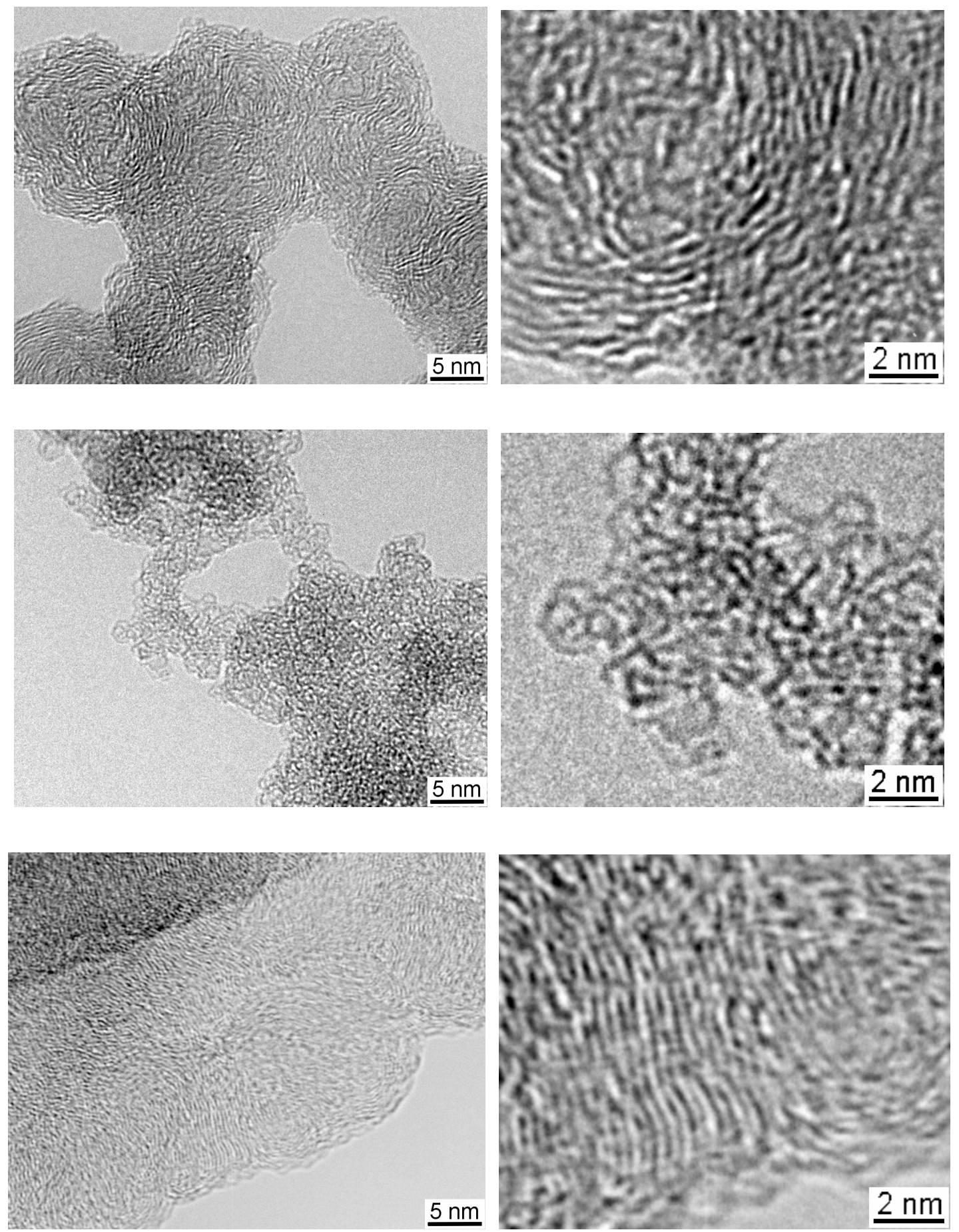

Fig. 3: HRTEM-micrographs of Euro IV soot from a low emission HD diesel engine (a, b),

GfG spark discharge soot (c, d), and hexabenzocoronene and (e, f). 


\section{Discussions}

It is accepted that soot from various sources are structurally similar, and similar to commercial carbon black; that is, consisting of primary spherical particles of $20-30 \mathrm{~nm}$ in diameter coagulated to chain-like aggregates. The primary particles consist of graphene segments or basic structure units (BSU) of $1.2-1.4 \mathrm{~nm}$ thickness [14] arranged concentrically, parallel to the particle perimeter. There are two to five platelets of hexagonal face-centred arrays of carbon atoms per segment of BSU. The microstructure of Euro IV HD soot studied in the present work is obviously different from this structure model. The averaged particle size of Euro IV HD soot is $13 \mathrm{~nm}$, much smaller than the well accepted values for soot [15]. Other than for a few spherical particles, the majority of the primary particles do not exhibit a core-shell structure. Multiple-shelled particles with fullerenoid structure and inhomogeneous graphene segments are found in viewing high-resolution electron micrographs, characterised by the defective surface structure. The change in the microstructure of Euro IV HD soot implies a different soot formation mechanism $[16,9]$.

The difference in the oxidation behaviours of Euro IV HD soot, GfG soot, and HBC is associated with the different initial microstructures of the three samples, as clearly revealed by high-resolution images in Fig. 3. The main differences are the curvature of the graphene segments and exposure of basal and prismatic planes of graphene layers. It is well known that graphite oxidation proceeds anisotropically, i.e. the reactivity of basal plane carbon atoms is far lower than that of edge site carbon atoms. Carbon atoms in edge sites can form bonds with chemisorbed oxygen due to the availability of unpaired $\mathrm{sp}^{2}$ electrons, while carbon atoms in basal planes are more aromatic having only shared $\pi$ electrons to form chemical bonds [17]. The high resistance of $\mathrm{HBC}$ against gasification is due to the large graphite-like crystallites as big as several nanometers (Fig. 3c) that give a low ratio of edge site carbon atoms and basal plane carbon atoms, and a lower initial surface area. 
The explanation of the low initial temperature of oxidation of GfG soot is seen in the strongly curved fullerenoid structure of the primary particles with defective surface (Fig. 3e and 3d). The defective non six-membered rings may produce highly localised olefinic electronic structures prone to the addition of molecular oxidant. The defective surface can be easily functionalised with volatile or reactive groups. This results in an easier oxidation of the GfG soot which starts already at $420 \mathrm{~K}$. The GfG soot shows two pronounced maxima in $\mathrm{CO}_{2}$ evolution, the first at about $620 \mathrm{~K}$ has a higher $\mathrm{H}_{2} \mathrm{O} / \mathrm{CO}_{2}$ ratio, indicating the combustion of functionalised defect-rich primary particles. The second maximum in $\mathrm{CO}_{2}$ production is accompanied by a smaller $\mathrm{H}_{2} \mathrm{O}$ signal and is most likely due to the combustion of large primary particles or agglomerates with less defective/functionalized surfaces. However, the higher oxidation temperature could also be partly due to the amount of fullerenes in the GfG soot produced in the spark discharge of graphite. Earlier experiments on $\mathrm{C}_{60}$ oxidation in $5 \%$ $\mathrm{O}_{2}$ in $\mathrm{Ar}$ have shown that $\mathrm{C}_{60}$ has a well-defined onset of reactivity at $670 \mathrm{~K}$ [18]. The $\mathrm{H}_{2} \mathrm{O}$ signals obtained in high temperature regions could be due to the oxidation of the functional groups embedded in larger particles and agglomerates.

HBC exhibited sharp peaks of $\mathrm{CO}_{2}$ and $\mathrm{H}_{2} \mathrm{O}$ at $870 \mathrm{~K}$, which implies a relatively well-defined reactivity dominated by elements of graphite black chemistry, as confirmed by highresolution image showing regular stacks of planar BSU. Our study indicates that $\mathrm{HBC}$ can be suitable as a two-dimensional model system for a graphene sheet. Both are quite similar as they contain planar six-membered carbon rings of aromatic characters. The large $\mathrm{H}_{2} \mathrm{O}$ peak obtained with $\mathrm{HBC}$ is indicative of the hydrogen from the $\mathrm{C}_{42} \mathrm{H}_{18}$ molecule, and gives some idea of the ratio of carbon to hydrogen in the soot samples, the Euro IV soot having the lowest ratio of hydrogen to carbon. However, for the new Euro-IV HD diesel soot where the primary particles are made of extended flat as well as bent BSUs (Fig. 3b) due to the non-sixmembered carbon rings, HBC, with only 6 membered rings, cannot alone serve as a structural 
model system. Electronically, the new Euro IV HD soot may exhibit less aromatic, but rather more olefinic character at localised defects as well as $\mathrm{sp}^{3}$ character, due to strong curvature [19].

Euro IV HD soot is special in its structure. It differs from the commercial carbon black in size and in the stacking of BSU, and it also differs from GfG soot and HBC as revealed in Fig. 2. In general, the Euro IV HD soot is more fullerenoid- or "onion"-like with several closed carbon sheets. Careful study of high-resolution TEM reveals both bent and flat BSU, most of them stacked parallel due to van der Waals interaction typical for $\mathrm{sp}^{2}$ carbon. The primary particles are characterised by the discontinuous arrangement of bent and flat BSUs and nonsmooth surface structure. The defective structure of the periphery, with a high ratio of nonsix-membered rings of carbon, can be the host for oxygenated functional groups that release $\mathrm{H}_{2} \mathrm{O}$ during oxidation.

Fig. 3 indicates that GfG soot is a mixture of two types of material, a lower burning fraction with high $\mathrm{H}: \mathrm{C}$ ratio which has a maximum rate of combustion at about $620 \mathrm{~K}$, and a higher burning fraction with a low $\mathrm{H}: \mathrm{C}$ ratio that has a maximum rate of combustion at about $790 \mathrm{~K}$.

\section{Conclusion}

Optimization of the Euro IV HD engine has not only increased its efficiency for combustion, decreasing the amount of soot production up to $80 \%$ (compared to Euro III), but it has also changed the character of the soot produced. The Euro IV HD soot has a smaller primary particle size. Structurally, the Euro IV HD soot is more fullerenoid- or more "onion"-like with several closed carbon sheets, and these differences in morphology are also expressed as differences in reactivity. Advancement of the evolving soot after-treatment technology will need to take into account changes in the soot morphology, and the corresponding changes in reactivity. 
The gasification profile of the Euro IV HD soot is similar to that of the HBC, but with a maximum rate of combustion at $830 \mathrm{~K}, 40 \mathrm{~K}$ higher than the maximum rate of combustion for GFG, and $50 \mathrm{~K}$ lower than the maximum rate of combustion for HBC: the reactivity of the Euro IV HD soot is just between that of HBC and of GfG soot. Thus HBC and GfG can be regarded as model substances representing lower and upper limits of diesel soot reactivity.

\section{Acknowledgement}

This work is part of the project „Katalytisches System zur filterlosen kontinuierlichen Rußpartikelverminderung für Fahrzeugdieselmotoren“ supported by the Bayerische Forschungsstiftung. 


\section{Reference}

[1] http://www.dieselnet.com/standards (2003)

[2] E. Jacob, N. D’Alfonso, A. Döring, S. Reisch, D. Rothe, R. Brück, P. Treiber, PMKAT: Nichtblockierende Lösung zur Minderung von Dieselruß für Euro IV-HD Nutzfahrzeugmotoren, H.P. Lenz (Hrsg.) 23. Internationales Wiener Motorensymposium, 25.-26. April 2002, Band 2: Fortschritt-Berichte VDI Reihe 12 Nr. 490 Düsseldorf: VDI-Verlag 2002, S. 196-216

[3] B.R. Stanmore, J.F. Brilhac, P. Gilot, Carbon 39 (2001) 2247

[4] J.P.A. Neeft, T.X. Nijhuis, E. Smakman, M. Makkee, J.A. Mulijn, Fuel 76 (1997) 1129

[5] R. L. Vander Wal, A. J. Tomasek, Combustion and Flame 134 (2003) 1

[6] D.S. Su, J.-O. Müller, R.E. Jentoft, D. Rothe, E. Jacob, R. Schlögl, Topics in Catalysis, submitted

[7] A. Oberlin, High Resolution TEM Studies of Carbonization and Graphitization, in: P. Thrower (Edt.), Chemistry and Physics of Carbon 22, Dekker, New York (1989) 21142

[8] E. Clar, The Aromatic Sextet, $1^{\text {st }}$ ed. 1972, London: John Wiley and Sons

[9] E. Jacob, D. Rothe, R. Schlögl, D. S. Su, J.-O. Müller, R. Niessner, C. Adelhelm, A. Messerer, U. Pöschl, K. Müllen, C. Simpson, Z. Tomovic, Dieselruß: Mikrostruktur und Oxidationskinetik, H.P. Lenz (Hrsg.) 24. Internationales Wiener Motorensymposium, 15.-16. Mai 2003, Band 2: Fortschritt-Berichte VDI Reihe 12 Nr. 539 Düsseldorf: VDIVerlag 2003, S. 19-45

[10] C. Helsper, W. Mölter, F. Löffler, C. Wadenpohl, S. Kaufmann, G. Wenninger, Atmosp. Environment 27A (1993) 1271

[11] D. E. Evans, R.M. Harrison, J.G. Ayres, J. Aerosol Sci. 34 (2003) 1023

[12] C. Kübel, K. Eckhard, V. Enkelmann, G. Wegner, K. Müllen, J. Mater. Chem 10 (2000) 879

[13] M. Müller, J. Petersen, R. Strohmeier, C. Günther, N. Karl and K. Müllen, Angew. Chem., 1996, 108, 947; Angew. Chem., Int. Ed. Engl., 1996, 35, 886.

[14] T. Ishiguro, Y. Takatori, K. Akihama, Combust Flame 108 (1997) 231-234

[15] D.S. Su, J.-O. Müller, D. Rothe, E. Jacob, R. Schlögl to be published

[16] J.B. Heywood, Internal combusion engine fundamentals, New York: McGraw Hill, 1990 